\section{Practical Child and Adolescent Psychopharmacology}

Edited by Stan Kutcher. Cambridge:

Cambridge University Press. 2002. 482 pp.

Ł44.95 (pb). ISBN 0 52I 655420

This is a solidly written text, edited by a leading Canadian professor in the field of child psychopharmacology. The contributors are some of the foremost figures from the North American continent. Extensive references are given for each chapter, but rarely dated past 1998, highlighting the claim of some proponents of evidencebased medicine that 'the textbook' is obsolete, given the rapidity of knowledge expansion and electronic publication. Typical neuroleptics, for example, are advocated as the first-line intervention for schizophrenia, with little discussion of the atypical agents, which is striking in a text published in 2002.

A clear and well-argued introductory chapter reviews previous and current attitudes to paediatric psychopharmacology. Developmental issues are explored thoroughly from a basic science perspective, but it is clear that the clinical implications of the huge explosion of information in developmental brain science has not yet been integrated into clinical practice and 'more research is needed' is a frequent refrain. Dimensional (symptom) $v$. categorical (diagnosis) assessment structures are discussed. The argument favours the dimensional, with the implication that medication should be chosen, and its effects assessed, based on the presence of (target) symptoms, rather than theoretical diagnostic entities. 'Polypharmacy' follows logically from this and is encouraged if

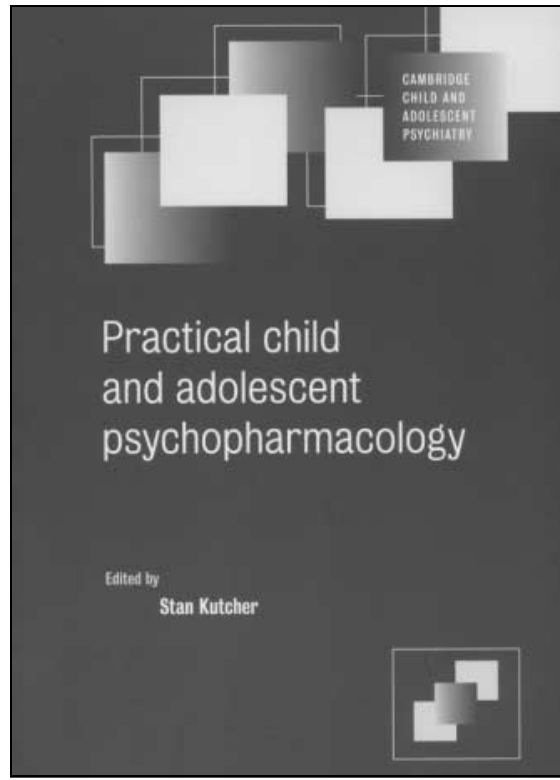

are covered in one sentence and adjunctive psychological treatments are not mentioned, the approach being purely pharmacological.

So who is the book written for? The aim at a biopsychosocial approach suggests the generic child mental health worker, but the basic science and adult literature reviews are irrelevant for them. The child and adolescent psychiatrist in training or in the child and family clinic should not need tables or DSM-IV diagnostic criteria or advice on non-pharmacological management to make an assessment and initiate treatment, but would benefit from the review of the adult literature and the principles of extrapolation to their patient group. The tertiary specialist will be frustrated by the lack of discussion of augmentation strategies and medication interactions, particularly given the wealth of experience of the authors. It is not comprehensive enough to be a general textbook of child and adolescent psychiatry, and there are more focused texts available on paediatric psychopharmacology. However, many paediatricians (and some adult psychiatrists) find themselves having to treat common child mental health problems, and for them this text is an excellent guide to the management of common problems, supporting their use of medication and guiding them to seek psychological and systemic approaches when appropriate.

approach is, for the most part, firmly eclectic, advocating school-, individualand family-based interventions, alongside or instead of medication, depending on the circumstances. However, this is not universal and, surprisingly, in the management of schizophrenia, psychosocial factors
S. Maskey Consultant Child and Adolescent Psychiatrist, Oak View Hospital, Crockenhill Road, St Mary Cray, Orpington, Kent BR5 4ES, UK 